\title{
Floral Diversity in Different Types of Honey
}

\author{
Susana Linhares Haidamus ${ }^{12}$ \\ https://orcid.org/0000-0002-0428-9193
}

Maria Cristina Affonso Lorenzon ${ }^{\text {* }}$

https://orcid.org/0000-0003-2771-3177

Adriano Soares Koshiyama ${ }^{3}$

https://orcid.org/0000-0001-7536-1503

\section{Wagner de Sousa Tassinari ${ }^{4}$}

https://orcid.org/0000-0002-3799-1261

\begin{abstract}
${ }^{1}$ Animal Science Postgraduate Program at Federal Rural University of Rio de Janeiro (UFRRJ), Rio de Janeiro, Brazil; ${ }^{2}$ Animal Science Institute of the Federal Rural University of Rio de Janeiro (UFRRJ), Rio de Janeiro, Brazil; ${ }^{3}$ Computer Science Postgraduate Program at University College London (UCL), London, United Kingdom; ${ }^{4}$ National Institute of Infectious Diseases at Oswaldo Cruz Foundation (FIOCRUZ), Rio de Janeiro, Brazil
\end{abstract}

Received: 2018.05.13; Accepted: 2019.08.13.

*Correspondence: affonsoneta@gmail.com; Tel.: +55-21-37873975 (M.C.A.L.)

\section{HIGHLIGHTS}

- Among 152 samples of honey, 60 pollen types were found belonging to 27 plant families.

- From 152 honey samples, 58\% are unifloral honeys, 35\% polyfloral and $7 \%$ bifloral

- Wild plants were the main origin of the most honey samples

- Why do unifloral honeys predominate in the market?

Abstract: Many different types of honey are available in the Brazilian market. They vary in color, flavor, smell, thereby increasing interest in honey characterization relating to botanical origin. A total of 155 honey samples belonging to Brazilian flora were examined on the pollen analysis; sampling is made in a span of one year. The preparation followed melisso palynological analysis based on the specific botanical variety. The pollen spectra revealed 60 pollen types belonging to 27 plant families and Myrtaceae, Fabaceae and Asteraceae were the dominant plant families. Few pollen types were found in most samples of honey. The families that showed major richness of pollen types were Fabaceae and Asteraceae. Only six floral sources of pollen plants and three floral sources of nectar plants appeared in 
the category of predominant pollen. The unifloral honeys were slightly more frequent than polyfloral, and wild floral species dominated most of the honey samples. These floral sources, even in minor parts in the honeys samples, are also part of the biological feature of theses honeys. The honeys from natural fields cannot be completely accounted by the term unifloral honeys.

Keywords: Plant diversity; pollen analysis; trophic niche; Ecology, conservation.

\section{INTRODUCTION}

Honeybees (Apis mellifera) are important pollinators due to their contribution to the maintenance of ecosystems and agricultural activities. The magnitude of bee's pollination actions for food production reaches orders between $15 \%$ and $30 \%[1,2,3]$.

In Brazil, the value of pollination services is subjective, despite the significant growth of agribusiness. The biggest relevance in Africanized bee (Apis mellifera) exploration goes mainly toward honey production and other bee products. Honeybee experts believe that foraging patches are often composed of native plants, which produce organic types of honey that are attractive to the market [4].

The advancement of anthropogenic actions, accompanied with pollution complexity, is a constant threat to natural ecosystems, and the decline in bee species and the contamination of their products are alarming issues $[5,6,7,8]$. Threatened of such losses are the honey plants. Whether these plants are a natural occurrence or cultivated for honey purposes, they require favorable conditions to grow and provide nectar for honeybees. The limitations of this specific flora must be recognized, and the different sources of each type of honey should be located and protected. Therefore, identifying the botanical and geographic origins of commercial honey is critical [9].

Among the analyses of honey, Melissopalynology is recommended for apiarists according to Brazilian legislation [ ${ }^{9}$ ], although it is not mandatory [10]. This analysis enriches the scientific literature treating the floral sources of honey by studying the pollen types. In the southeast region of Brazil, some more recent studies could be cited [11,12], they have reported the high diversity of nectar and pollen sources for honeybees. They also reported that most types of honey come from wild melliferous plants such as Croton (Euphorbiaceae), Schinus (Anacardiaceae), Vernonia, and Gochnatia (Asteraceae).

A drastic reduction of the species in the tropical flora has been reported $[13,14,15]$ and researchers must provide a necessary update and deepen the knowledge about honey plants. This research focused on the identification of pollen types in honeys and their definition in unifloral and polyfloral in a mesoregional scale.

\section{MATERIAL AND METHODS}

Honey samples from honeybees (Apis mellifera, Africanized) were obtained by 187 varieties of unifloral and polyfloral samples. We gathered them in stores and apiaries from 51 different counties in the state of Rio de Janeiro, Brazil. Of the total samples, 35 were discarded from 33 regions, they had a low count of pollen grains, which was insufficient for the analysis. 
Identifying the pollen types: (a) Qualitative method. The pollen types present in the honey were determined via comparison with reference blade samples deposited in the pollen voucher (the reference pollen slide collection from the Laboratory of Palynology, Department of Botany, Institute of Biology, Universidade Federal do Rio de Janeiro) and by the descriptions obtained from the literature [9]. Each pollen type found in the samples was cataloged and photographed. (b) Quantitative method. After recognizing the pollen types, more than 300 pollen grains were counted [16].

The pollen types were classified in percentage and evaluated in standard classes according to Louveaux and coworkers [17]. The classes were: (a) dominant pollen class ( $>45 \%$ of the total pollen), (b) accessory pollen class $(15 \%-45 \%$ of the total pollen sum), and (c) important pollen class (3\%-15\% of the total pollen).

Honey based on floral sources: the honey samples were classified by the predominance of floral sources based on classes of frequencies of pollen types: (a) unifloral, when one pollen type was dominant; (b) polyfloral, when pollen types were of low frequency (called accessory pollen and isolated pollen) [9]. Bifloral honey was also included in this diagnosis, and it exhibited two pollen types as accessory pollen class. For certain honey samples with pollen grains that were sub-represented, such as Croton, Hyptis, Citrus, Vernonia, Anadenathera, a factor was necessary to apply, as recommended by Barth [9]. The terms "pollen and nectar plants" were assigned, due to the little knowledge available about the honey types. For Barth [12], it is necessary to consider the properties of the nectariferous or polliniferous species (nectar and pollen plants), previously presented, as to their sub- or over-representation in pollen grains.

Statistic procedures: the pollen types predominant in honey and the interval of confidence $(p=95 \%)$ of pollen frequencies were submitted to exploratory analysis. All the analyses were run by the statistics software R Studio [18].

\section{RESULTS}

Pollen diversity of honeys: Among 152 samples of honey from Africanized honeybees, 60 pollen types were found to belong to 27 plant families and 34 genera (Table 1). Only 19 pollen types (32\%) are frequently observed (Table 2). On the basis of nectar flow, some types appeared in two categories, either as predominant or accessory. Only six species of pollen plants and three species of nectar plants appeared in the category of predominant pollen. Myrtaceae (26\%), Fabaceae (25\%) and Asteraceae (23\%) were the most frequent plant families; Fabaceae and Asteraceae present the highest number of pollen types (15 and 7 types, respectively). 
Table 1. Pollen types in honey samples of Apis mellifera from Rio de Janeiro, Brazil.

\begin{tabular}{lll}
\hline 1.Anacardiaceae & 21.Alternanthera (Amaranthaceae) & 41.Montanoa sp. (Asteraceae) \\
2.Araceae & 22.Anadenanthera spp. (Fabaceae) & 42.Piptadenia sp. (Fabaceae) \\
3.Arecaceae & 23.Arrabidea sp. (Bignoniaceae) & 43.Protium sp. (Burseraceae) \\
4.Asteraceae & 24.Bauhinia sp. (Fabaceae) & 44.Schizolobium sp. (Fabaceae) \\
5.Cyperaceae & 25.Baccharis sp.(Asteraceae) & 45.Schinus sp. (Anacardiaceae) \\
6.Caesalpiniaceae & 26.Brassica sp. (Brassicaceae) & 46.Serjania sp. (Sapindaceae) \\
7.Euphorbiaceae & 27.Carica sp. (Caricaceae) & 47.Senecio sp. (Asteraceae) \\
8.Fabaceae & 28.Cesalpinia sp. (Fabaceae) & 48. Tapirira sp. (Anacardiaceae) \\
9.Loranthaceae & 29.Copaifera sp. (Fabaceae) & 49.Trema sp. (Cannabaceae) \\
10.Myrtaceae & 30.Croton spp. (Euphorbiaceae) & 50.Triplaris sp. (Polygonaceae) \\
11.Musaceae & 31.Desmodiun sp. (Fabaceae) & 51.Vernonia sp. (Asteraceae) \\
12.Malvaceae & 32.Eucalyptus sp. (Myrtaceae) & 52.Citrus sinensis (Rutaceae) \\
13.Rutaceae & 33.Eupatorium sp. (Asteraceae) & 53.Coffea arabica (Rubiaceae) \\
14.Rubiaceae & 34.Gochnatia spp. (Asteraceae) & 54.Elephantopis mollis (Asteraceae) \\
15.Sapindaceae & 35.Hyptis spp. (Lamiaceae) & 55.Mimosa aff. Acacia (Fabaceae) \\
16.Solanaceae & 36.Ilex sp. (Aquifoliaceae) & 56.M. caesalpiniaefolia (Fabaceae) \\
17.Verbenaceae & 37.Lindernia sp. (Linderniaceae) & 57.M. invisa (Fabaceae) \\
18.Acacia sp. (Fabaceae) & 38.Machaeriun sp. (Fabaceae) & 58.M. scabrela (Fabaceae) \\
19.Antigonon sp. (Polygonaceae) & 39.Myrcia sp. (Myrtaceae) * & 59.M. verrucosa (Fabaceae) \\
20.Allophylus sp. (Sapindaceae) & 40.Merremia sp. (Convolvulaceae) & 60.Ricinus communis (Euphorbiaceae) \\
\hline & &
\end{tabular}


Table 2. Exploratory analysis. Pollen types with greater frequency in honey samples from Rio de Janeiro, Brazil.

\begin{tabular}{|c|c|c|c|c|c|}
\hline Pollen types & $\mathbf{N}$ & Míni-Maxi & Median & VC & $\mathrm{Cl} 95 \%$ \\
\hline Asteraceae & 48 & $1.30-79.0$ & 10.2 & 099.5 & $13.3-24.1$ \\
\hline \multicolumn{6}{|l|}{ Pollen plants ${ }^{1}$} \\
\hline Anadenanthera sp. & 31 & $03.0-76.3$ & 18.0 & 095.2 & $20.0-39.4$ \\
\hline Arecaceae & 26 & $03.5-91.0$ & 10.0 & 107.1 & $09.4-24.3$ \\
\hline Eucalyptus sp. & 91 & 03.0-100 & 24.3 & 081.5 & $32.1-45.7$ \\
\hline Mimosa aff. Acacia & 14 & $03.2-15.2$ & 05.6 & 050.8 & $04.9-0.89$ \\
\hline Mimosa verrucosa & 17 & $04.0-92.8$ & 30.0 & 069.6 & $22.4-47.4$ \\
\hline Mimosa invisa & 08 & $03.0-42.0$ & 04.1 & 154.2 & $00.0-18.0$ \\
\hline Montanoa sp. & 11 & $06.4-71.2$ & 36.0 & 049.8 & $26.0-47.0$ \\
\hline Myrcia sp. & 46 & $03.0-95.3$ & 17.9 & 098.2 & $20.2-36.9$ \\
\hline Piptadenia sp. & 34 & $03.0-96.3$ & 18.0 & 089.2 & $17.9-34.1$ \\
\hline Ricinus communis & 09 & $03.2-50.0$ & 07.6 & 099.0 & $05.9-27.5$ \\
\hline \multicolumn{6}{|l|}{ Nectar plants ${ }^{1}$} \\
\hline Bauhinia sp. & 10 & $03.2-17.6$ & 08.1 & 054.1 & $05.3-11.8$ \\
\hline Citrus sinensis & 14 & $04.8-93.8$ & 31.7 & 084.2 & $18.3-52.9$ \\
\hline Croton spp. & 22 & $03.8-61.5$ & 16.5 & 067.7 & $13.7-25.4$ \\
\hline Elephantopus mollis & 10 & $03.0-50.0$ & 08.1 & 105.2 & $4.10-29.1$ \\
\hline Eupatorium sp. & 32 & $03.0-59.8$ & 19.1 & 070.6 & $16.2-27.3$ \\
\hline Gochnatia sp. & 09 & $04.6-95.3$ & 16.6 & 095.0 & $14.3-69.1$ \\
\hline Hyptis spp. & 13 & $03.0-07.6$ & 05.2 & 028.6 & $04.0-05.8$ \\
\hline Vernonia sp. & 23 & $03.0-72.4$ & 15.1 & 100.4 & $13.7-35.7$ \\
\hline
\end{tabular}

\section{Unifloral and polyfloral honeys}

Most honey samples were unifloral $(n=89 ; 58 \%)$ and, wild plants were the main origin of these honeys (Table 3). Unifloral honeys showed 3-4 pollen types (68\%); considering all samples the average was up to five pollen types. Such honeys which origin came from nectar plants, other types of sediments were commonly found, besides the specific pollen. These sediments included: (a) pollen grains from plants that did not produce nectar (as in Poaceae), and (b) pollen grains from facultative plants, whose presence is variable, depends on nectar production (e.g., Eucalyptus).

Unexpectedly, the frequency of polyfloral honey (35\%) and bifloral honey (7\%) is lower than that of unifloral honeys. Most of the samples ranged between 4-6 pollen types (57\%). Table 3 presents the identification of pollen frequency in unifloral and polyfloral honeys; the bifloral honeys presented the following floral species: (1) Eucalyptus and Myrcia, (2) Eucalyptus and Schinus, (3) Eucalyptus and Citrus, (4) Eupatorium and Vernonia, (5) Mimosa caesalpiniaefolia Benth and Piptadenia, (6) Elephantopus and Croton, (7) 
Anadenanthera and Acacia, (8) Piptadenia and Croton. Totalizing the samples of honeys, Eucalyptus sp. is the most frequent pollen type (Table 3).

Table 3. Pollen frequency in unifloral and polyfloral honeys from Rio de Janeiro, Brazil.

\begin{tabular}{|c|c|c|c|}
\hline Pollen types & & $\operatorname{APF}^{1}(\%)$ & $\mathrm{Cl}^{2} \mathbf{9 5} \%$ \\
\hline \multicolumn{4}{|c|}{ Unifloral honeys } \\
\hline Anadenanthera sp. & Fabaceae & $71.1(\mathrm{n}=7)$ & $67.3-74.9$ \\
\hline Citrus sinensis & Rutaceae & $67.1(n=5)$ & $36.5-97.7$ \\
\hline Eucalyptus sp. & Myrtaceae & $79.9(n=30)$ & $72.7-87.0$ \\
\hline Gochnatia sp. & Asteraceae & $88.9(n=3)$ & $66.3-100$ \\
\hline Mimosa verrucosa & Fabaceae & $66.8(n=4)$ & $31.6-100$ \\
\hline Montanoa sp. & Asteraceae & $60.5(n=3)$ & $37.0-83.9$ \\
\hline Myrcia sp. & Myrtaceae & $74.4(n=9)$ & $67.1-81.7$ \\
\hline Piptadenia sp. & Fabaceae & $70.4(n=4)$ & $39.8-100$ \\
\hline Vernonia sp. & Asteraceae & $62.3(n=7)$ & $52.0-72.6$ \\
\hline \multicolumn{4}{|c|}{ Polyfloral honeys* } \\
\hline Vernonia sp. & Asteraceae & $10.4(n=12)$ & $05.6-15.3$ \\
\hline Eupatorium sp. & Asteraceae & $21.9(n=14)$ & $13.7-30.2$ \\
\hline Arecaceae & & $24.1(n=12)$ & $09.0-39.1$ \\
\hline Mimosa verrucosa & Fabaceae & $29.6(n=10)$ & $20.1-39.1$ \\
\hline Anadenanthera sp. & Fabaceae & $13.7(n=14)$ & $08.2-19.2$ \\
\hline Piptadenia sp. & Fabaceae & $16.1(n=16)$ & $09.7-22.5$ \\
\hline Croton sp. & Euphorbiaceae & $15.6(n=11)$ & $10.7-20.6$ \\
\hline Eucalyptus sp. & Myrtaceae & $19.4(n=32)$ & $15.2-23.7$ \\
\hline Hyptis sp. & Lamiaceae & $05.0(n=11)$ & $03.9-06.1$ \\
\hline
\end{tabular}

Moreover, we highlight the honey from Gochnatia (wild plant), which is commonly classified as polyfloral. Comparing with some unifloral honeys, Gochnatia shows the highest interquartile of range $(\mathrm{AIQ}=67.24)$ (Figure 1) due to the high frequencies of some pollen types, which can hide the "real" nectar type. Thus, can the pollen type of Gochnatia subrepresented like others honeys, reported by Barth [9]. 


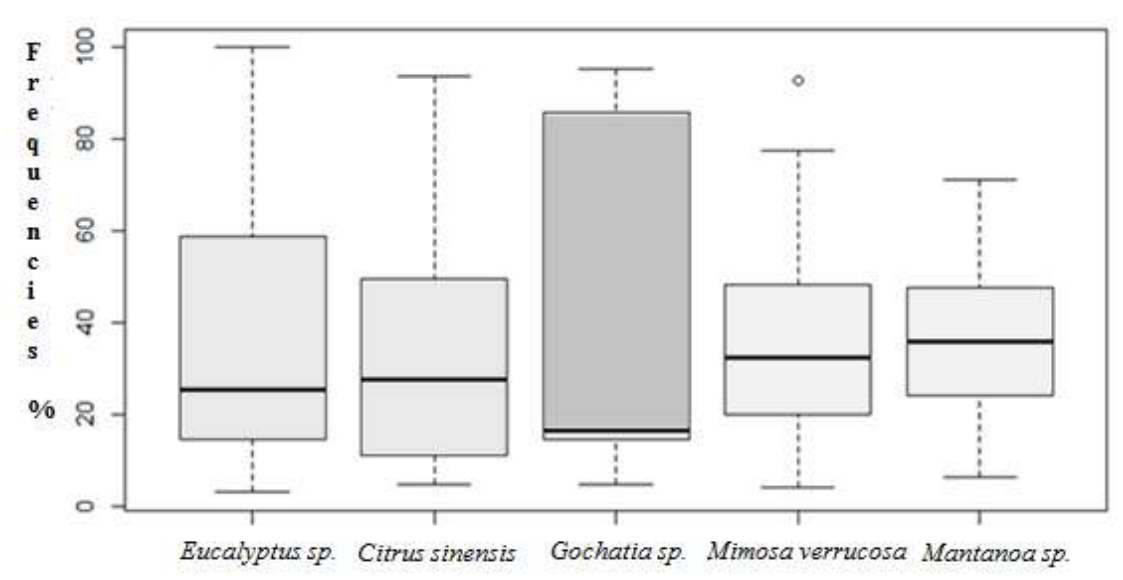

Figure 1. Box plots of pollen types frequencies in samples of honey from Rio de Janeiro.

\section{DISCUSSION}

Our research identified a significant diversity of plants in honeys. From 27 plant families, 60 pollen types contributed to the richness of honey commonly sold in stores in Rio de Janeiro, one of the most important honey markets in Brazil.

The dominance of two plant families and a few pollen types in most samples of honey led us to consider that this trend could be due to the forage behavior of Apis mellifera in this mesoregion. These results were familiar to the findings of previous studies of Ramalho et al. [19] and Modro et al. [20], who once reported Fabaceae and Asteraceae as the main floral sources in the southeast Brazil. In Rio de Janeiro, Barth and Luz [21] revealed Asteraceae, Fabaceae, Myrtaceae, Arecaceae and Mimosaceae as the main floral sources of high occurrence in honeys, and Luz et al. [22] added Euphorbiaceae to this list. In honey and pollen loads samples from the state of São Paulo, the most frequent plant families were Asteraceae, Bignoniaceae, Malpighiaceae and Myrtaceae [23].

In general, the wild plants predominated in honey sampling; this observation was also reported by Luz et al. [22]. The natural origin of such honeys gives it its high value in the market and brings Brazilian honey substantial interest from domestic and exterior markets. Such interest is unusual in countries with intense agriculture.

Among the wild flowering plants explored by the honeybees, some are frequently found in fragmented and recovering habitats such as liana, herb, shrub, and arboreal. Massflowering occurs in supertramp plants (high dispersion among many different habitats), none of which are particularly specialized [27], which are wide spread in several kinds of phytophysiognomies in the Atlantic Rainforest [28], an important biome in Rio de Janeiro. However, we found that few genera were supertramp (17.6\%, $\mathrm{n}=3)$ : Croton, Myrcia and Piptadenia. Thus, the honeybees forage wild and exotic plants in degraded areas in the borders of the Atlantic Rainforest or other types of vegetation. This observation was also reported by Braga et al. [30].

Actually Brazilian beekeeping uses fields from abandoned livestock and recovering habitats, where the diversity of wild plants is low, but flowering is massive and expressive throughout the year. These conditions are supported by significant honey harvests for beekeeping sector throughout the year [22]. 
However, that is not true for Atlantic Rainforest biome [31]. According to Bergallo et al. [32] many regions of the state of Rio present high rates of environmental devastation; livestock, banana, coconut and sugar cane crops are the potential generators of conflicts around environmental conservation and the living of small farmers. It is a fact that regions suitable for beekeeping are becoming increasingly rare and competitive. Lorenzon et al. [33] made a survey in state of Rio de Janeiro and found low honey production ( $<14 \mathrm{~kg} /$ hive/year) and high losses from hives due to hunger, in most micro regions; this profile indicates the low availability of primary resources for honeybees.

Thus, having a mean low of floral types (three and four) per honey sample is predictable with the loss of native flora. Other regions of Brazil showed a similar profile to previous works: Luz et al. [22] reported four and 11 pollen types per sample; Moreti et al. [24] found that the highest number of pollen types is 11 per sample; Osterkamp and Jasper [25] reported a range between seven and 15 pollen types per sample; Modro et al. [26], Barth [34] and, Barth and Luz [21] pointed out that regional and seasonal factors are responsible for the variation in pollen types in honeys. The size of the sampling is another relevant factor that affects the diversity of pollen types, despite the similarity of results. In addition, beekeeping and industrial management can also reduce the pollen types in honeys. Such issues should be further involved in honey studies using Palynology.

Unifloral and polyfloral honeys: The large production of honey in several regions of Brazil originates from native fields from certain abundant melliferous plants, are the ones that results in the production of unifloral honeys. The predominance of unifloral honey has also been demonstrated by Barros et al. [35] at the level of $54 \%(n=13)$. Similarly, Barth [12] reported that the predominance of unifloral honey was $57 \%(n=17)$.

Besides the 89 unifloral honey samples in our study, more honey were identified by previous researchers in the market of the state of Rio de Janeiro: Luz et al. [22] identified Lecythidaceae honey, whereas Barth [36] identified Borreria verticillate (L.) G. Mey (Rubiaceae) honey, Hyptis umbrosa Salzm (Lamiaceae), and Vernonia scorpioides (Lam) Pers. (Asteraceae) honeys.

Some caution must be taken to interpret the origin of certain unifloral honeys, such as Eucalyptus (and Citrus). The state of Rio de Janeiro is an importer of large volume of eucalyptus honey that dominates the production of the states of São Paulo and Minas Gerais (personal observations). Some beekeepers who bought this honey, mix with other types and sell in Rio de Janeiro market. That evidence explains why Eucalyptus sp. is the most frequent pollen type in honeys (Table 3 ) and its dominance hide the real origin of the unifloral and polyfloral honeys, especially those that come from native regions with high diversity of wild plants, whose pollen types still little known.

Thus we have the dominance of unifloral honeys and, low diversity of pollen types in our sampling. Besides the possible poor contribution of degraded areas to available bee food and, the typical behavior of honeybees to recruit many forager bees to attend fields containing few mass-flowering species with high amounts of attractive nectar. Such floral species occurs a few times in a year [34, 37].

Otherwise, unifloral and polyfloral honeys are also subjected to certain factors that influence their occurrence, such as those which can be attributed to hive management by 
beekeepers and industrial processes, can also affect their occurrence as follows: (a) mixture of combs from different hives during harvests; (b) no selection of combs based on the time of use; (c) incorrect use of filters during honey processing (fine filters can retain large pollen grains); (d) diversity of habitats that can enrich the diet of honeybees, mainly in pollen sources. These managements can influence the difference between the low representativeness of certain pollen plants and their available nectar during honey flow in the field. The blossoms of Croton sp., Eupatorium, Vernonia, and Gochnatia are some examples, each honey of that flower species has low presence of pollen itself, and its nectar is abundant and attractive for forager bees. In these cases, if it is difficult identify honeys by pollen types, sensorial analysis should be conducted.

Beekeepers are advised to include a description of the floral field when working with wild plants, especially those in high density, and such information can help identify the plant sources and properties. However, this information is not mandatory and also the analysis of pollen types in honeys [10].

Classifying honey as unifloral or polyfloral. Although Melissopalynology enriches data about flora in honey studies, it is not absolute. As previously discussed, eucalyptus honey whose pollen load can be high, can hide the real nectar plant (s) source (s) of honey, but not the sensorial type.

In this sequence, the honey from Gochnatia in our study demands increased attention (Figure 1). This plant is wild and classified as a pioneer, growing spontaneously in fields and pastures in the remaining habitats of the Atlantic Rainforest [38, 34]. The flowering of this plant occurs twice a year, with a low range between events. The blossom is also short, and lasts only 15 days. Despite the intensive nectar flow, the hives do not complete their supers with mature which results in polyfloral honey, featuring the flowering of Gochnatia (with high proportion of nectar than pollen) and another less expressive flowering (low floral density). However, in the major samples of this honey, the flavor and color (sensorial analyses) are characteristic for Gochnatia blossom, allowing this honey to be identify immediately. Thus, sensorial analysis is may be precise in the classification of this floral source and support the use of the term unifloral honey. However, that classification may not be appropriate either.

These accounts bring to light some discussions on the classification of honey as emphasized by Molan [39]. Fallico et al. [40] and Kropf et al. [41] reported that unifloral types of honey are rare in wild field, and hard to produce; moreover, their main floral source is challenging to identify based on the honey. Lianda [42] used chemical markers and noticed certain floral species with low pollen representation in honey, are those with a high representation of phenolic substances. Can et al. [43] demonstrated the actual quality of honey associated with the presence, variety and amounts of its bioactive compounds, and these factors depend on the geographic and floral structure of the region in which is produced.

In fact, the term unifloral honey in beekeeping sector is associated with the honey which results from hives used in plantations to pollinate and that represents the floral source. In large agricultural fields, the diet of bees has been poor in pollen types. 
Although most characteristics of honey are compatible with honey classification by pollen type, the standards developed by this analysis should be flexible to accommodate changes as more data become available. Such as the floral sources of honeys those are in minor part, but they are part of the biological feature of these honeys. Thus, the true quality of honeys originating from natural fields cannot be completely accounted by the term "unifloral honey", and the identification of its flora requires special sampling.

The best way to represent the value of honey is its all-natural sources, so the classification of honey as an organic food can be better viewed, comprehended and respected.

Acknowledgments: We are grateful to Conselho Nacional de Pesquisa Científica e TecnológicaCNPq for support this research, including scholarships and, to Ortrud Monika Barth (FIOCRUZ) for suggestions and pollen analysis.

Funding: This study was financed in part by Conselho Nacional de Pesquisa Científica e Tecnológica-CNPq-Brasil (process 578134/2008-0, CNPQ 064), and supported by a master fellowship - CAPES.

Conflict of interest: The authors declare no conflict of interest.

\section{REFERENCES}

1. Mcgregor SE. Insect Pollination of Cultivated Crop Plants. Washington (DC): U.S. Department of Agriculture-Agricultural Research Service; 1976.

2. Roubik DW. Pollination of cultivated plants in the tropics. Rome: FAO Agricultural Services Bulletin; 1995.

3. Deplane KS, Mayer DF. Crop pollination by bees. Wallingford: CABI Publishing; 2000.

4. Abemel. (Brazilian beekeeping sector in numbers). Associação Brasileira de exportadores de mel [Internet]. [place unknown: publisher unknown]; [updated 2017]. Avaliable from:

http://www.conap.coop.br/wp-content/uploads/2017/01/intelig\%c3\%8ancia-comercial-.abemel dezembro-consolidado.pdf.

5. Freitas BM, Imperatriz-Fonseca VL, Medina LM, Kleinert AMP, Galetto L, Nates-Parra G, et al. Diversity, threats and conservation of native bees in the Neotropics Apidologie. 2009; 40:332-46. doi:10.1051/apido/200901.

6. Mullin CA, Frazier M, Frazier JL. High levels of miticides and agrochemicals in North American apiaries: Implications for honeybee health. PLoS One. 2010;5(3): e9754. doi:10.1371/journal. pone. 0009754.

7. Potts SG, Kremen C, Schweiger O, Kunin WE. Global pollinator declines: trends, impacts and drivers. Trends Ecol Evol. 2010;25(6):345-53. doi:10.1016/j.tree.2010.01.007.

8. Bovi TS. (Toxicity of insecticides for bees Apis mellifera L.) Brasil: Universidade Estadual Paulista Júlio Mesquita Filho; 2013.

9. Barth OM. (Pollen in Brazilian honeys). Rio de Janeiro: Luxor; 1989.

10. Brasil. Portaria N. 006 de 25 de julho de 1985. Ministério da Agricultura. Secretaria Nacional de Defesa Agropecuária. Secretaria de Inspeção de Produto Animal. Hygienic-Sanitary and Technological Norms for Honey, Beeswax and Derivatives. Brasilia: SIPA; 1985.

11. Moreti ACC, Marchini C, Souza VC, Rodrigues RR. (Pollen atlas of melliferous plants). Rio de Janeiro: Papel e Virtual; 2002. 44 p.

12. Barth OM. (Pollen analysis of honey: evaluation of data and their meaning). Mensagem Doce Magazine. 2015;81. Avaliable from: htpp://www.apacame.org.br 
13. Brasil. (The Convention on Biological Diversity-CDB), Cópia do Decreto Legislativo no 2 , de 5 de junho de 1992, p.30. Brasília: Ministério do Meio Ambiente; 2002.

14. Scheffers BR, Joppa LP, Pimm SL, Laurance WF. What we know and don't know about Earth's missing biodiversity. Trends Ecol Evol. 2012; 27:501-10. doi:10.1016/j.tree.2012.05.008.

15. Pimm SL, Jenkins CN, Abell R, Brooks TM, Glittleman JL, Joppa LN, et al. The biodiversity of species and their rates of extinction, distribution, and protection. Science. 2014; 344:1246752. doi:10.1126/science.1246752.

16. Maurizio A, Louveaux J. Pollens de plantes mellifères d Éurope. Paris: UGAF; 1965. 148 p.

17. Louveaux J, Maurizio A, Vorwohl G. Methods of melissopalinology. Bee World. 1978; 59:139-57.

18. R Studio. [Internet]. [place unknown: publisher unknown]; [updated 2017] Avaliable from: http://rstudio.org.

19. Ramalho M, Kleinert-Giovannini A, Imperatriz-Fonseca VL. Important bee plants for stingless bees (Melipona and Trigonini) and Africanized honeybees (Apis mellifera) in neotropicais habitats: a review. Apidologie. 1990; 21:469-88. doi:10.1051/apido:19900508.

20. Modro AFH, Message D, Pinto da Luz CF, Neto JAAM. Flora of polyniferous importance for Apis mellifera (I.) in the region of Viçosa, state of Minas Gerais (Brazil). Rev Árvore. 2011;35(5):114553.

21. Barth OM and Luz CFP. Melissopalynological data obtained from a mangrove area near to Rio de Janeiro, Brazil. J Ap Res. 1998; 37:155-63. doi:10.1080/00218839.1998.11100967.

22. Luz CFP, Thomé ML and Barth OM. (Trophic resources of Apis mellifera L. (Hymenoptera, Apidae) in the region of Morro Azul do Tinguá, State of Rio de Janeiro (Brazil). Braz J Botany. 2007;30(1):47-65. doi:10.1590/S0100-84042007000100004.

23. Mendonça K, Marchini LC, Souza BA, Almeida-Anacleto D, Moreti ACCC. (Melliferous plants for Apis mellifera L. (Hymenoptera: Apidae) in fragments of Cerrado vegetation, Itirapina, SP). Neotropical Entomology 2008;37(5):513-21.

24. Moreti ACC, Carvalho CAL, Marchini LC, Oliveira PCF. (Pollen spectrum of honey samples of Apis mellifera L., collected in the state of Bahia (Brazil). Bragantia. 2000;59(1):1-6.

25. Osterkamp IC, Jasper A. (Palynological analysis on honeys from the Taquari Valley region, Rio Grande do Sul, Brazil: tool for definition of botanical origin). Rev destaques acadêmicos. 2013;5(3):111-9.

26. Modro AFH, Message D, Pinto da Luz CF. Survey of bee pollen from the region of Viçosa, state of Minas Gerais (Brazil), between August and December 2005. Braz J Biosciences. 2007; 5:6546.

27. Diamond JM. Colonization of Exploded Volcanic Islands by Birds: The Supertramp Strategy". Science. 1974;184(4138):803-6. doi:10.1126/science.184.4138.803.

28. Oliveira-Filho AT, Fontes MAL. Patterns of floristic differentiation among Atlantic Forests in southeastern Brazil and the influence of climate. Biotropica. 2000; 32:793-810. doi: 10.1646/00063606(2000)032[0793: pofdaa]2.0.co;2

30. Braga JA, Sates EO, Soares-Neto J, Conde MM, Barth OM, Lorenzon MCA. Floral sources to Tetragonisca angustula (Hymenoptera: Apidae) and their pollen morphology in a Southeastern Brazilian Atlantic Forest. J Trop Biol. 2012;60(4):1491-501.

31. Lorenzon MCA, Conde MMS, Barbosa CG. Eusocial Apidae in Tropical Insular Region. Braz Arch Biol Technol. 2006;49(5):733-8. doi:10.1590/S1516-89132006000600007. 
32. Bergallo, et al. Estratégias e ações para a conservação da biodiversidade no Estado do Rio de Janeiro. Instituto BIOMAS. 2009. 344p.

33. Lorenzon MCA, Koshiyama AS, Haidamus SL, Muniz Jr JCB. Indicators and challenges of Beekeeping from state of Rio de Janeiro, a Brazilian portrait. Editora Above. 2012, 271p.

34. Barth OM. Monofloral and wild flower honey pollen spectra at Brazil. Ciência e Cultura. 1996; 48:163-5.

35. Barros LB, Torres FR, Barth OM, Freitas MQ. Evaluation of honey produced in different flowering in Paraíba do Sul - RJ. In: Il Mostra UFF em Higiene e Tecnologia de Alimentos. Anais. Niterói: UFF; 2009. 56p.

36a. Barth OM. Microscopic analysis of some samples of honey. 1. Dominant Pollen. An Acad Bras Ciênc. 1970; 42:351-66.

36b. Barth OM. Microscopic analysis of some samples of honey. 2. Accesory Pollen. An Acad Bras Ciênc. 1970; 42:571-90.

36c. Barth OM. Microscopic analysis of some samples of honey.3. Isolated Pollen. An Acad Bras Ciênc. 1970; 42:747-72.

37. Seeley TD. The wisdom of the hive - The social physiology of honeybee colonies. London: Harvard University Press; 1995. 317p.

38. Barth OM. Pollen in monofloral honeys from Brazil. J Ap Res. 1990; 29:89-94.

39. Molan P. The limitations of the methods of identifying the floral source of honey. Bee World. 1998;79(2):59-68.

40. Fallico B, Zappala M, Arena E, Verzera A. Effects of conditioning on HMF content in monofloral honeys. Food Chem. 2004; 85:305-13. doi:10.1016/j.foodchem.2003.07.010.

41. Kropf U, Bertoncelj M, Ogrinc J. Determination of the geographical origin of Slovenian black locust, lime and chestnut honey. Food Chem. 2010;121(3):839-46. doi:10.1016/j.foodchem.2009.12.094.

42. Lianda RLP. Profile of Brazilian honeys phenolic substances by high performance liquid chromatography and evaluation of the antioxidant potential. Brasil: Universidade Federal Rural do Rio de Janeiro; 2009.

43. Can Z, Yildiz O, Sahin H, Turumtay EA, Silici S, Kolayli S. An investigation of Turkish honeys: Their physico-chemical properties, antioxidant capacities and phenolic profiles. Food Chem. 2015; 180:133-41. doi:10.1016/j. foodchem.2015.02.024.

(c) 2018 by the authors. Submitted for possible open access publication under the terms and conditions of the Creative Commons Attribution (CC BY NC) license (https://creativecommons.org/licenses/by-nc/4.0/). 